\title{
Skills Gap and Upskilling: Isolating and Reducing the Gap in MENA e-Businesses
}

\author{
Lara CHAAYA, Jennifer ABOU HAMAD and Ghassan BEYROUTHY
}

Notre Dame University, Louaize, Lebanon

Correspondence should be addressed to: Jennifer ABOU HAMAD; jabouhamad@ndu.edu.lb

Received date:19 February 2019; Accepted date:7 October 2019; Published date: 6 November 2019

Academic Editor: Yosra Essid Hamas

Copyright (C 2019. Lara CHAAYA, Jennifer ABOU HAMAD and Ghassan BEYROUTHY. Distributed under Creative Commons CC-BY 4.0

\begin{abstract}
The twenty-first century brought with it technological advancements, increasing business demands, and massive economic crises that have forced many professions to be reinvented over and over again. Employers all around the world are demanding greater levels of skills from their employees, and this trend appears to be applicable to the Middle East and North African region as well. This paper uses a quantitative research method to identify the critical skills required for senior-level employees to perform successfully in e-businesses and to explore the gap between the industry's expectation and satisfaction with the skills of their employees. The study was based on survey responses from 147 people working in ebusinesses in Saudi Arabia, Lebanon, and United Arab Emirates. One sample t-tests were performed to identify the importance that the industry placed on 20 skills relevant to ebusiness and to explore the satisfaction of the industry with the performance of its seniorlevel employees in these specific skills. The findings showed that senior-level employees exhibit a more significant skills gap in soft skills than in digital skills, especially in decision making, leadership, and problem-solving skills. The results highlight the need to develop soft skills among candidates before they enter the workforce and offer educational institutions guidance for redesigning coursework to prioritize soft skills that are most relevant to the workplace. The findings also suggest that firms invest in the continuous learning of their employees to avoid the need to look for new people whenever the market changes.
\end{abstract}

Keywords: Skills gap, senior-level employees, e-business, MENA Region

Cite this Article as: Lara CHAAYA, Jennifer ABOU HAMAD and Ghassan BEYROUTHY (2019)," Skills Gap and Upskilling: Isolating and Reducing the Gap in MENA e-Businesses", Journal of Human Resources Management Research, Vol. 2019 (2019), Article ID 519819, DOI: 10.5171/2019.519819 


\section{Introduction}

The interest in e-business began back in 2013, when the Central Bank of Lebanon (BDL) issued a circular by which it instituted a new policy to de-risk investments in technology-based startups. Based on the circular, $\$ 400$ million will be guaranteed by up to $75 \%$ for Lebanese banks' equity investments in startups, incubators, accelerators, and funds in the digital sector (Rimington-Pounder, 2016). In the UAE, the value of investments in ebusinesses has reached almost two thirds of the total value of investments in the five Middle Eastern countries with the highest shares of investment deals combined at \$139 million (Bizri, 2016). In Saudi Arabia, the Vision 2030 and the National Transformation Program (NTP) 2020 have set forth numerous initiatives in technology and innovation aiming to shift Saudi Arabia from an oil-dependent economy to a knowledge-based economy (ArabNet, 2017). According to ArabNet (2018), Saudi Arabia ranks among the top 5 countries in the MENA region with the highest number of equity investments in digital startups, making the Kingdom a hotspot of startup activity.

The boom of the digital sector in MENA is not without its difficulties. One of the critical challenges impeding the sustainable growth of companies in the digital sector is finding employees with key skills, and this is a challenge that is being faced across industries and sectors, not only regionally but all across the globe. A report in 2014 examined challenges faced by around 200 companies in hiring and retention requirements. The study showed that nearly $80 \%$ of respondents say they suffer from a lack of skills in their talent pool (Gaul, 2014). What is even more alarming is that most of this gap occurs in the roles that are very critical to the organizations' growth and that require highly skilled resources (Erickson, Schwartz, \& Ensell , 2012). For many companies, talent is the number one resource and the basis of their competitive advantage (Arms \& Bercik, 2013)

Experts have tried to identify the reasons leading up to the skills gap (Arms \& Bercik,
2013; PwC, 2014; Gaul, 2014; Tempesta \& Vona, 2015). They claim that megatrends such as technological development (Gaul, 2014; Tempesta \& Vona, 2015), globalization, automation, sophisticated customers, demographic change, and urbanization are transforming the world and the business landscape along with it (PwC, 2014; Tempesta \& Vona, 2015). And amidst all this change, companies are struggling to come to terms with an evolving workforce governed by an influx of millennials who, unlike the older generation that remained with one employer for a lifetime, prefer a much more mobile and independent career (Arms \& Bercik, 2013; PwC, 2014). Moreover, the increasing competitive markets which companies are operating in today are forcing business leaders to look for people with a far wider range of skills than ever before (PwC, 2014). As a result, the demand for quality talent and skills has become very high (Arms \& Bercik, 2013).

This paper attempts to answer the following main research question: "To what extent does a skills gap exist in senior-level positions in e-businesses operating in the MENA?"

To answer this question, a quantitative methodology was used where primary data were collected from both employers and employees working in e-businesses across Saudi Arabia, Lebanon, and UAE. The findings and results of this research will identify the gap between the important skills needed for the success of e-businesses and the performance of senior-level employees in these skills.

\section{Literature Review}

The twenty-first century brought with it technological advancements, increasing business demands, and massive economic crises that have forced many professions to be reinvented over and over again, with employers demanding different skill sets at different times (Thomson, 2009). Employers all around the world are demanding greater levels of skills from their employees (OECD, 2011), and this trend appears to be applicable to the Middle East 
and North African region as well (Baqadir et al., 2011; Bayt.com \& YouGov, 2016). According to Thomson (2009), organizations are placing increasing emphasis on "hiring candidates with the right skill sets right from the start" even if the skills required are very job-specific, but this is proving to be very challenging. In fact, a report by Careerbuilders (2013) shows that 61 percent of organizations surveyed globally claim to have hired a person who does not fully meet the stated requirements for a job.

A mismatch between the skills required by employers and those possessed by employees can be detrimental to both the organization and the employee: important tasks would no longer be carried out effectively and efficiently, potentially reflecting negatively on the bottom line and leading to moral and ethical compromises (Thomson, 2009). This skills mismatch raises concerns on the ability of societies to capitalize on their workforces, especially in developing countries, where a lack of sufficient skills in the workforce can compromise economic development (Shwalje, 2011).

A skills mismatch in the workforce occurs when the skills possessed by employees and the skills that employers look for are different (WEF, 2014; Gaul, 2014; Thomson, 2009;). The literature mentions different types of skills mismatch, all of which coexist in the modern labor market. When there are skills not possessed by currently employed individuals but which employers think are necessary for the organization's performance (Hart et al., 2007), a skill gap occurs (CEDEFOP, 2012; WEF, 2014; OECD, 2011), and it will be the focus of this study.

\section{Employer's Perception of the Skills Gap regardless of Sector}

Although the research on the skills gap has gained much attention over the last thirty years (Kamalakar, 2014), a review of the literature shows that little research has been done on the skills gap among seniorlevel employees from the perspective of their employers. Nevertheless, there is consistent evidence that employers believe a skills gap exists among their employees in general. For example, when 2000 managers were asked about their observations of a skills gap in Australian firms across sectors, $75 \%$ reported a skills gap, and 33\% reported a skills gap across the entire organization (Lindroff, 2011). The study indicates that although employees show strong proficiency in basic skills, they lack leadership, management, and industryspecific skills in the viewpoint of their employers. In fact, McIlvaine (2012) posits that Chief Executive Officers (CEOs) are greatly concerned about their managers not having the right skills to navigate in today's complex and every-changing economy. Garwood (2012) concurs, stating that in the United Kingdom, organizations are being forced to invest more money to train their managers with communication and problem-solving skills because they are not adequately competent to deal with the challenges of the modern workplace. According to Seetha (2014), almost 50\% of employers surveyed admit that their workers would benefit from additional training and development. However, many firms lack in-house training programs (Seetha, 2014), and a vast majority (60\%) acknowledge that even though they considered running a training program, they have not done anything in this regard (PwC, 2014).

Several studies try to pinpoint the type of skills most lacking among employees. A study in the United States shows that more than $60 \%$ of employers consider that their senior-level employees are incompetent when it comes to communication and interpersonal skills, and this represents a $10 \%$ increase over the course of just two years (Seetha, 2014).

Soft skills are perceived to be a source of skills gaps in employers' opinion, particularly communication and teamworking skills, followed by problem-solving skills (Learning and Skills Council, 2007). These claims are somehow similar to the findings by Hall and Rogers (2014), who confirm that communication skills are not adequate in firms, yet the most significant skill deficiency is problem-solving skills. 
When it comes to digital skills, a study by Capgemini Consulting (2013) reveals that $90 \%$ of the interviewed companies witness a serious skills gap in social media, mobile, data analysis, and process automation. Despite the fact that an overwhelming majority $(87 \%)$ of these firms consider digital transformation as a competitive advantage, a mere $46 \%$ are investing efforts to develop digital skills among their workforce.

\section{The Nature of the Skills Gap in E- Business}

The terms "e-business" and "e-commerce" are often used synonymously (Zwass, 2014), although there is a clear distinction between them. E-business is the use of the internet, intranets, extranets, and other networks to conduct and empower business processes. These electronic business processes can include electronic commerce, payment processing, information sharing, recruiting, organizational communication, internal collaboration between employees and external collaboration with customers, suppliers, business partners, and other stakeholders (Combe, 2012). E-commerce represents presale marketing, sales transactions, or after-sales services of products and services via computer networks (Burkey, 2002). Actually, ecommerce is considered a subset of ebusiness, because the latter includes a broader range of activities in addition to the sales transactions with suppliers and/or customers.

Most of the research studying the skills gap in e-businesses mainly discusses the deficiency in digital skills without examining if other interpersonal, cognitive, or self-awareness skills are also lacking (Cassano, 2002; Petrova \& Claxton, 2005). One of the few studies that investigate both soft and technical skills in e-business is that by Petrova and Claxton (2005), which found that employers ranked the ability to learn, self-confidence, and knowledge of the business are the three most critical soft skills for business success, while e-business development, project planning, and data analytics were ranked as the three most critical digital skills; the results of the study also showed that these critical skills are severely absent in the firms of the surveyed employers (Petrova \& Claxton, 2005).

There is a general consensus that digital skills are scarce all around the world (Benni et al, 2016), particularly in the Middle East (Bayt.com \& YouGov, 2016), yet the demand for highly skilled technical talent to run a fast-growing digital economy has never been this high. According to an Oxford Economic survey (2012), the most critical technical skills needed today are digital business skills. According to Cassano (2002), one of the major challenges that firms, particularly small and medium enterprises, in the digital sector face today is the lack of IT skills and knowledge about e-business. Without these skills, seniorlevel employees find it difficult to take informed decisions and manage operations in the most effective and efficient way.

\section{Methodology}

\section{Strategy and Tools}

A quantitative methodology was used to identify the skill gap. The tool used is electronic surveys distributed randomly to people registered in ArabNet's database and working in the digital sector in Saudi Arabia, Lebanon, and the UAE. A total of 402 people were contacted through an e-mail which explained the purpose of the study and had a link to the survey. In the email, the people were also asked to forward the link of the survey to other people they know who also work in the digital sector, which is a form of snowball sampling. Snowball sampling is a type of sampling method often used with difficult-to-reach populations to ensure that the highest possible number of targeted people is contacted (Sadler, Lee, Lim, \& Fullerton, 2010). A total of 197 responses were collected, out of which 147 responses were valid. The other responses were discarded either because they belonged to people who worked outside the digital sector, such as in schools or brick-andmortar retail shops, or because their answers to the control questions disqualified them, or the key questions of the survey were left unanswered. 
The survey used as the instrument tool for the quantitative study was designed based on a comprehensive list of 40 industryrelevant skills defined by Jackson (2010). This list was mapped to the findings in the literature review to select 20 of the most critical skills that many employers across industries look for in their employees.

Those skills are: critical thinking, problem solving, decision making, oral communication, leadership, teambuilding, diversity management, multitasking, organizational skills, accountability, personal and work ethics, knowledge of the business, quantitative skills, application and use of technology, writing skills, resistance to change, embracing organizational culture, social media skills, big data analytics, and online marketing.

The questionnaire had two main sections: the first section asked demographic questions such as age, gender, job position, years of work experience, and others; the second section asked participants to rank the importance of each of the 20 listed skills that they thought were critical for the successful performance of senior-level employees working in an e-business. The ranking was based on a five-point Likert scale, where 1 meant 'least important' and 5 meant 'most important.' Then, the participants were asked to rank their level of satisfaction with the senior-level employees' performance on each of the skills, also using a five-point Likert scale where 1 meant 'least satisfied' and 5 meant 'extremely satisfied.'

The data collected were imported to SPSS in order to conduct an in-depth analysis using descriptive statistics

\section{Profiling the Participants in The Study}

The majority of the respondents are males, at 68.7 percent. Almost $47 \%$ percent of the respondents are between 30 and 39 years old, 38.1 percent are between 20 and 29 years old, and 15 percent are above 40 years old.

Most of the survey respondents worked in Lebanon (35.4\%), UAE (34\%), and Saudi
Arabia (17\%), which are the countries this study focuses on. The other respondents are scattered in different countries across the Middle East and North African region, such as Egypt, Jordan, Kuwait, Qatar, and others.

Most of the survey respondents (43.5\%) had job positions equivalent to directors, general managers, or C-level officers such as COO or CEO. Senior-level employees with job positions equivalent to managers constituted $29.9 \%$ of the survey respondents, and $26.5 \%$ were mid- or entry-level employees, as shown in the figure below.

\section{Results and Findings}

Many studies that explore the skills gap between employers' perception and expectation rely on descriptive statistics to rank the importance of the skills as perceived by the employers and to rank the skills that the sample under study is most and least competent at (Ramadi, Ramadi, \& Nasr, 2016; Shuayto, 2001; Zaharim, Zaidi Omar, \& Basri, 2009).

Likewise, this study uses descriptive statistics to explore the skills gap. The survey examined a total of 20 skills. Survey respondents rated the importance of skills and their satisfaction with senior-level employees' skill levels on a scale of 1 to 5 (Likert Scale), with 1 being extremely important or extremely satisfied, and 5 being extremely unimportant or extremely unsatisfied. Since the data are parametric, the means for importance and satisfaction were calculated with $90 \%$ confidence intervals using the one sample $t$-test method.

\section{Skill Importance}

After conducting the one sample t-test, the skills were ranked according to their mean importance in order to identify which skills were perceived as the most critical by people working in the digital sector. The skill "resistance to change" has the smallest mean (2.54); because it has a value less than three, this skill is considered to be unimportant for e-business senior-level employees. In fact, this skill was used as a control variable in the electronic survey, which explains its low value. 
All the remaining skills have values greater than three, so they are all considered to be important for e-business senior-level employees, but at varying degrees. The skill considered to be the most important according to the mean ranking is problem solving (4.7). The second most important skill is personal and work ethics (4.55), followed closely by critical thinking (4.53), decision making (4.5), accountability (4.48), knowledge of the business (4.43), leadership (4.4), and oral communication (4.39). The skills that were considered least important, yet still considerably important, are online marketing (3.5) and social media skills (3.33), both of which are digital skills.

\section{Skill Satisfaction}

Skills were also ranked based on the respondents' mean satisfaction with the performance of senior-level employees with each skill. Interestingly, all skills have mean values greater than three, meaning that people are generally satisfied with the skills of senior-level employees. However, the overall mean values of skill satisfaction is lower than the overall mean values of skill importance. This will be further examined in the Skill Gap Analysis section further in this chapter.

Based on the mean ranking of skill satisfaction, both employers and employees are very satisfied with the senior-level employees' knowledge of the business, with a mean value of 4.14 . Other skills that employers and employees are satisfied with include personal and work ethics (3.99), problem solving (3.83), and application and use of technology (3.83). The least satisfactory skills, although still considerably satisfactory, are leadership (3.52), teambuilding (3.51), social media skills (3.48), and online marketing (3.35).

\section{Skill Gap}

The skills gap is calculated by subtracting the mean value attributed to the importance of a skill and the mean value attributed to the satisfactory performance level of that skill.
According to the skills gap analysis using mean values, all skills except one exhibit a skills gap, but with varying degrees. The two skills with the largest gap are decision making and leadership. The only skill that featured no gap is social media skills; on the contrary, it showed a negative value, indicating that the level of satisfactory performance of senior-level employees in social media skills is higher than the level of importance of that skill.

\section{Reliability}

A commonly used objective measure of reliability is Cronbach's alpha, which examines the internal consistency of the items within a test to ensure that they are all closely related and they all measure the same concept. The acceptable values of Cronbach's alpha range from 0.70 to 0.95 (Tavakol \& Dennick, 2011). Cronbach's Alpha for the skill importance variable set is 0.796, and Cronbach's Alpha for the skill satisfaction variable set is 0.929 verifying that the variables in both sets are closely related and the test is reliable.

\section{Conclusion}

The one sample $t$-test revealed that soft skills are more critical and have a more significant gap than digital skills in ebusinesses. These results are concurrent with similar research done in the region (Bayt.com \& YouGov, 2016). In decreasing order, problem solving, personal and work ethics, critical thinking, decision making, and accountability scored the largest mean values for skill importance, while online marketing and social media skills scored the least mean values for skill importance. Even though soft skills were found to be the most critical, the one sample $t$-test also revealed that the skills gap was most significant in soft skills. The skill with the largest skill gap (mean difference value) is decision making, followed by leadership, and problem solving.

One limitation to the study emanates from the use of a mixed sampling method to contact the hard-to-reach population. Although most participants were randomly selected from ArabNet's database, some 
participants were contacted through the use of the snowball sampling. While the snowball sampling has its limitations, this study applied the statistical requirements needed to produce reliable results. The reliability of the study was further confirmed with the test of Cronbach's Alpha.

As mentioned above, the participants involved in this study are part of ArabNet's network which is largely concentrated in Saudi Arabia, Lebanon, and UAE. Hence, this study is limited to the experiences of people within these three countries. Nevertheless, reports have indicated that these three countries have the most active digital economies in the MENA region (ArabNet, 2017; Bayt.com \& YouGov, 2016), and therefore can be used as a base for initial research on the e-business sector.

Additionally, while this study tries to generalize its findings across the MENA, a small percentage of the respondents were based in Saudi Arabia. Moreover, MENA region encompasses a vast geographical area with a wide variety of cultures, and perceptions may differ from one region to the other. Hence, more localized research is recommended to offer more representative results that could be generalized across the MENA.

There are several implications to this study. Firstly, the findings of this research showed that the most critical skills for senior-level employees are soft skills rather than technical, or digital, skills. While training programs could be more efficient in improving and developing the technical skills of senior-level employees, soft skills are more difficult to acquire, especially at a late stage in one's career. This implies that soft skills should be learned early on, preferably during a person's undergraduate studies. Educational institutions could create a positive change in the workforce by creating new curricula that integrate the anticipated business requirements with the development of essential critical skills such as decision making, leadership, and problem solving.

Additionally, the apparent skills gap that currently exists in the e-business sector implies that having senior-level employees with the key skills is a competitive advantage for the business; hence, employers could use this insight to create attractive retention programs to decrease the risk of other competitors snatching key employees with alluring benefits.

Last but not least, it is evident from this study that firms need to invest in the continuous learning of their employees, starting from the entry-level employees, to foster a workforce that have the needed cognitive and interpersonal skills to operate in the modern workplace. This implies the need is for business leaders to realize that new skills does not necessarily mean new people, but rather upskilling and nurture of the existent employees to become effective senior-level employees.

\section{References}

1. ArabNet . (2017), 'The state of digital investments in MENA 2013-2017'. [Online]. ArabNet. [Retrieved January 22, 2018], https://www.arabnet.me/english/business -intelligence/the-state-of-digitalinvestments-in-mena-2013-2017-report 2. ArabNet. (2018), 'KSA innovation economy'. [Online]. ArabNet. [Retrieved February 5, 2019], https://www.arabnet.me/english/business -intelligence/ksa-innovation-economy--tech-startups-2017-report

3. Arms, D., \& Bercik, T. (2013), 'Filling jobs wisely: How companies use talent supply chain management to link human capital to business needs,' Strategic Finance, 39-43.

4. Baqadir, A., Patrick, F., \& Burns, G. (2011), 'Addressing the skills gap in Saudi Arabia: does vocational education address the needs of private sector employers?' Journal of Vocational Education \& Training, 63(4), 551-561.

5. Bayt.com, \& YouGov. (2016), 'The Skills Gap in the Middle East and North Africa: A Real Problem or a Mere Trifle?' YouGove and Bayt.com. [Retrieved March 20, 2017], https://d25d2506sfb94s.cloudfront.net/r/ 17/The\%20Skills\%20Gap\%20in\%20MEN A\%20WhitePaper\%202016.pdf

6. Bizri, L. (2016), 'Investments in the MENA region - the state of digital investments in mena'. [Online]. ArabNet. 
Retrieved May 3, 2017, from http://news.arabnet.me/investments-inthe-mena-region-the-state-of-digitalinvestments-in-mena-report/

7. Burkey, J. L. (2002), 'Electronic commerce education: An analysis of practitioner and academic perceptions of essential skills and knowledge', Graduate Schools of the University of Sarasota, Faculty of the University of Sarasota.

8. Capgemini Consulting. (2013), 'Digital Skills Survey.' [Online]. Capgemini Consulting. [Retrieved May 26, 2017], https://www.capgemini.com/wpcontent/uploads/2017/07/the_digital_tale nt_gap27-09_0.pdf

9. Careerbuilder. (2013), 'The shocking truth about the skills gap.' [Online]. Careerbuilder. [Retrieved June 1, 2017], http://cleanenergyexcellence.org/wpcontent/uploads/2014/08/ShockingTruth-Skills-Gap.pdf

10. Cassano, G. (2002), The business of ebusiness.' Australian CPA, 72(1), 64-66.

11. CEDEFOP. (2012), Future skills supply and demand in Europe. Publications Office of the European Union, Luxembourg.

12. Combe, C. (2012) Introduction to eBusiness Management and Strategy. Elsevier, Oxford.

13. Erickson, R., Schwartz, J., \& Ensell , J. (2012), 'The talent paradox: critical skills, recession, and the illusion of plentitude'. Deloitte Review, 10: 78-91

14. Garwood, R. (2012), 'Supporting the underperforming manager: Teaching the soft skills that can make all the difference.' Human Resource Management International Digest, 20(1), 39-42.

15. Gaul, P. (2014), 'Talent acquisition requires strategic use of social media, understanding quality of hire.' TD, 22.

16. Gorman, M. F. (2011), 'A case study in effectively bridging the business skills gap for the information technology professional.' Journal of Education for Business, 17-24.

17. Hall, T., \& Rogers, C. O. (2014), 'A skills map for Indiana.' Indiana Business Review. 18. Jackson, D. (2010), 'An international profile of industry-relevant competencies and skill gaps in modern graduates.' International Journal of Management Education, 8(3), 29-58.
19. Jackson, D., \& Chapman, E. (2011), 'Nontechnical skill gaps in Australian business graduates.' Education + Training, 54(2/3), 95-113.

20. Kamalakar, M. (2014) 'A study of the skill development strategies in the context of rapid changing environment in selected industries.' Osmania University, Department of Business Management, Hyderabad.

21. Kim, Y., Hsu, J., \& Stern, M. (2006), 'An update on the IS/IT skills gap.' Journal of Information Systems Education, 17(4), 395402.

22. Learning and Skills Council. (2007) National Employers Skills Survey 2007: Key Findings. Learning and Skills Council, England.

23. Lindroff, M. (2011) 'Skills gaps in Australian firms.' Journal of Vocational Education \& Training, 63(2), 247-259.

24. Mcllvaine, A. R. (2012), 'Facing the human risk factor: Corporate leaders at the nation's largest companies are taking steps to manage what has been identified as one of the top risks facing businesses: a shortage of qualified talent.' Risk \& Insurance, 88-89. 25. Benni, E. Elmasry T., Patel, J. Moore J. P. (2016) 'Digital Middle East: Transforming the region into a leading digital economy.' [Online]. Digital McKinsey. [Retrieved November 20, 2016], https://www.mckinsey.com/featuredinsights/middle-east-and-africa/digitalmiddle-east-transforming-the-region-intoa-leading-digital-economy

26. OECD. (2011) Skills for Innovation and Research. OECD Publishing.

27. Oxford Economics. (2012), Global Talent 2021: How the new geography of talent will transform human resource strategies. Oxford Economics.

28. Petrova, K., \& Claxton, G. (2005), 'Building student skills and capabilities in information technology and ebusiness: a moving target.' Journal of Information Systems Education, 16(1), 27.

29. PwC, (2014) 'The talent challenge: Adapting to Growth,' PwC 17th Annual Global CEO Survey: Transforming talent strategy

30. Ramadi, E., Ramadi, S., \& Nasr, K. (2016), 'Engineering graduates' skill sets in the MENA region: a gap analysis of industry 
expectations and satisfaction.' European Journal of Engineering Education, 41(1), 3452.

31. Rimington-Pounder, S. (2016) Circular 331: Where has Lebanon's money gone? [Online]. Wamda. [Retrieved May 3, 2017] https://www.wamda.com/2016/04/circul ar-331-where-has-lebanons-money-gone 32. Sadler, G. R., Lee, H. C., Lim, R. S., \& Fullerton, J. (2010),' Recruitment of hardto-reach population subgroups'. Nursing and Health Sciences, 12(3), 369-374.

33. Seetha, N. (2014), 'Are soft skills important in he workplace? A preliminary investigation in Malaysia.' International Journal of Academic Research in Business and Social Sciences, 4(4).

34. Shuayto, N. (2001), 'A study evaluating the critical managerial skills corporations and business schools desire of MBA graduates.' Wayne Huizenga Graduate School of Business and Entrepreneurship, Florida.

35. Shuayto, N. (2013), 'Management skills desired by business school deans and employers: an empirical investigation.' Business Education \& Accreditation, 5(2), 93-105.
36. Tavakol, M., \& Dennick, R. (2011), 'Making sense of Cronbach's alpha.' International Journal of Medical Education, 2, 53-55.

37. Tempesta, A., \& Vona, M. K. (2015), 'A lack of talent: Why and how insurers should act today to drive future success in a changing claims landscape.' Best's Review, pp. 70-74.

38. Thomson, J. C. (2009), 'The skills gap and business performance.' Corporate Finance Review, 13(5), 19-21.

39. WEF, (2014), Matching Skills and Labour Market Needs: Building Social Partnerships for Better Skills and Better Jobs. Global Agenda Council on Employment at the World Economic Forum (WEF): Switzerland

40. Zaharim, A., Zaidi Omar, M., \& Basri, H. (2009) 'A gap study between employers' perception and expectation of engineering graduates in Malaysia.' WSEAS Transactions on Advances in Engineering Education, 6(11), 409-419.

41. Zwass, V. (2014) The framework and the big ideas of e-business, Handbook of Strategic e-Business Management, F. J. Marinez-Lopez (ed), Springer-Verlag, Berlin. 